\title{
Frequency and Clinical Manifestations of Scabies in Suspected Patients Referred to Health Centers of Kashan, Central Iran (2010 -
}

\section{4)}

\author{
Sima Rasti, ${ }^{1}$ Mehdi Nazeri, ${ }^{1}$ Elahe Kaveh, ${ }^{1}$ Rezvan Talaee,,${ }^{2,}$ and Seyed Gholam Abbas Mousavi ${ }^{3}$ \\ ${ }^{1}$ Department of Parasitology, Faculty of Medicine, Kashan University of Medical Sciences, Kashan, IR Iran \\ ${ }^{2}$ Department of Dermatology, Autoimmune Diseases Research Center, Faculty of Medicine, Kashan University of Medical Sciences, Kashan, IR Iran \\ ${ }^{3}$ Department of Statistics and Public Health, Faculty of Health, Kashan University of Medical Sciences, Kashan, IR Iran \\ "Corresponding author: Dr. Rezvan Talaee, Department of Dermatology, Assistant Pro. Faculty of Medicine, Kashan University of Medical Sciences, Kashan, IR Iran. Tel: \\ +98-9133613767, E-mail: r_talaee2007@yahoo.com
}

Received 2016 May 12; Revised 2016 July 18; Accepted 2017 February 08.

\begin{abstract}
Background: Scabies is one of the most common itching contagious skin disorder in the world. The agent of disease is Sarcoptes scabiei.

Objectives: This study was conducted to determine the frequency and clinical manifestations of S. scabies in suspected patients referred to health centers of Kashan during 2010 - 2014.

Methods: This cross-sectional study was performed on 129 patients suspected to Sarcoptes scabiei. The demographic and clinical symptoms for each of patients were recorded in questionnaire by interview. A deep skin scrap was prepared and wet smear were prepared using $10 \% \mathrm{KOH}$. By observation of each form of Sarcoptes was identified as positive sample. The data were recorded in Spss. ver 16.5 and analyzed by X2 and fisher exact tests.

Results: The results of this study showed that 28 (21.7\%) were Sarcoptes positive. The frequency of sarcoptes was higher in males (23\%) than females (20.6\%). The difference was not statistically significant. The most cases were isolated in spring and winter. Sarcoptes infestation was the most in elderly and patients undergone dialysis. There is significant difference between disease and age group and underlying disease $(\mathrm{P}=0.03, \mathrm{P}=0.014$; respectively). Erosion or pustule was the most clinical signs in positive cases.

Conclusions: The results of study showed that the rate of scabies infestation in Kashan is relatively high, and the most cases were in elderly patients. Health education to increase awareness of the families for prevention of scabies was recommended.
\end{abstract}

Keywords: Infestation, Sarcoptes scabiei, Kashan, Iran

\section{Introduction}

Scabies is a ubiquitous ectoparasite infestation which defined as neglected skin disease [1]. The cause of human scabies is Sarcoptes scabiei var. hominis which is an Acarina mite belong to the Astigmata order [2-5]. It is an obligate parasite to humans and highly contagious disease which is known as one of the most common pruritic dermatitis among the poor populations in the less developed countries [6-8]. Among different symptoms pruritic papular lesion,excoriation, and burrow are more common, so that patients with nocturnal pruritus would be consider as Scabies suspected case [6]. Allergic sensitivity to the mite or its products appears to play an important role in determining the development of lesions other than burrow, and in producing pruritus [7]. Scabies is usually transmitted by close physical contact, such as prolonged hand-holding or the sharing of a bed. Although several studies have shown that this infection could be transmitted by indirect methods such as sharing of clothes [7].
It has been estimated about 300 million people affected annually in worldwide and the most cases were reported from developing countries as a major public health problem and most cases were young children $[1,9]$. This could be due to lack of immunity and a high chance of exposure in this group. Despite common belief, the Prevalence of scabies between both sexes and among different ethnic groups is similar and some factors such as overcrowding, housing, socioeconomic and cultural habits could be justified these differences $[1,10,11]$. Although the infectious agent of Scabies is ubiquitous, the underprivileged communities are more endemic and naturally are more engaged in many social problems such as Poverty, poor nutritional status, homelessness and poor health care [10]. High temperature, humidity and crowded places such as military camps can increase the incidence of scabies infestation [12].

However, in developed countries outbreaks occur in hospitals, kindergarten, nursing homes, prisons and refugee camps $[1,13,14]$. 
Scabies in Iran like other country which located in the Middle East is considered as a major public health problem $[3,15]$. Several studies have shown different rate of scabies infestation $1.3 \%$ - 57\%, which these differences were related to geographical area and years of study $[3,16]$. Treatment of scabies can be done by permethrin, lindane, benzyl benzoate, sulfur, ivermectin, crotamiton and other remedies [6].

The aim of this study was determination of frequency of S. scabies infestation and related factors in central of Iran.

\section{Methods}

This cross- sectional study was conducted on the 129 patients with pruritus suspected to scabies infestation referred to Shahid Beheshtei laboratory, and Fatemieh health care center, Kashan, Iran during 2010 - 2014. The demographic and epidemiological criteria, furthermore clinical symptoms of patients were recorded in a questionnaire by interview. The sampling was carried out by using scraping test. After disinfection of skin with 70\% alcohol, a deep skin scrap was prepared using disposable scalpel and wet mount smear was prepared using 10\% potassium hydroxide $(\mathrm{KOH})$ to clear the specimen. The mite infestation was identified by observation of each form of Sarcoptes such as adult mites with spherical shape, four pairs of legs, hind legs end in long bristles, nymph or oval clear eggs with 0.1$0.15 \mathrm{~mm}$ long .At least three slides for each patient was prepared $[6,7]$.

\subsection{Statistical Methods}

All the data were recorded in SPSS software version 16.5 (SPSS Inc., Chicago, IL) and were analyzed using the ChiSquare and Exact Sig Chi-squared test. P value less than 0.05 considered as significant. This study was approved by the ethical committee of Kashan University of Medical Sciences, Iran.

\section{Results}

The mean age of study group was $39 \pm 20.9$, which the least age was one month and the greatest was 90 years old. Based on the results of this study the prevalence of Scabies was 28 cases (21.7\%) (Table 1 ).

Out of twenty eight positive cases, the highest rate of scabies was reported during 2014 (35.7\%) and the least one in 2011 (3.8\%) respectively $(\mathrm{P}=0.045)$.

The highest rate of scabies infestation was among the 60 - 79 years old (41.4\%), while the least rate was $(6.5 \%)$ among 20 - 39 years old $(\mathrm{P}=0.03)$ (Table 2$)$.
Overall the results showed that the most rates of scabies were seen $33.3 \%$ and $26.3 \%$ in spring and winter respectively $(\mathrm{P}=0.068$. $)$

The most common symptoms and signs were pruritus and erosion $27(96.4 \%)$ and $8(28.6 \%)$ in the positive cases, respectively (Table 3 ).

Their family of the majority of positive cases 19 (67.8\%) suffered from scabies, too. The highest rate of infestation was reported in sexual partner (25\%), and the lowest in the grandson. $(\mathrm{P}=0.000)$. The most positive cases of scabies were patients undergone dialysis $75 \%(\mathrm{P}=0.014)$. The highest rates of recognized form of sarcoptes were 22 (78.6\%) adult mites, 5 (17.9\%) eggs and one nymph (3.6\%) (P $=0.000)$.

Table 1. Distribution of Demographic Data in the Sacoptes Infestation in Suspected Patients Referred to the Health Centers of Kashan During $2010-2014^{\mathrm{a}}$

\begin{tabular}{|c|c|c|}
\hline & Total Number & Positive \\
\hline \multicolumn{3}{|l|}{ Sex } \\
\hline Female & 68 & $14(20.6)$ \\
\hline Male & 61 & $14(23)$ \\
\hline Total & 129 & $28(21.7)$ \\
\hline \multicolumn{3}{|l|}{ Education } \\
\hline Illterated & 47 & $15(31.9)$ \\
\hline Primary & 67 & $11(16.4)$ \\
\hline College & 15 & $2(13.3)$ \\
\hline \multicolumn{3}{|l|}{ Living place } \\
\hline Urban & 114 & $24(21.1)$ \\
\hline Rural & 15 & $4(26.7)$ \\
\hline
\end{tabular}

${ }^{\mathrm{a}}$ Values are expressed as No (\%)

\section{Discussion}

Scabies is one of the most common pruritic contagious skin disorders; defined as a huge social problem in the poor communities with weak public health system $[15,17$, $18]$.

The results of present study showed that $21.7 \%$ of cases were infested by S. scabies. The Confidence of interval with $95 \%$ is; $\mathrm{CI}=21.7 \pm 0.32$. These findings were similar to Jalayer et al. study (28.2\%) in Isfahan; a city is not far away from our study place [19]. Reduced rates of scabies (1.3\%, $2.09 \%$ ) in primary school were reported by Golchai and Sharif et al. respectively $[16,20]$. However, this different rate of scabies infestation could be related to difference the studied populations. The highest rate (57\%) of scabies was reported among prisoners in Bandar Abbas in south of Iran 
Table 2. Distribution of Sacoptes Infestation According to Age Groups in Suspected Patients Referred to the Health Centers of Kashan During 2010 - $2014^{\mathrm{a}}$

\begin{tabular}{l|c|c|c|}
\hline Ag, $\mathbf{y}$ & Positive & Negative & Total \\
\hline$\leq \mathbf{2 0}$ & $6(28.6)$ & $15(71.4)$ & $21(100)$ \\
\hline $\mathbf{2 0}-\mathbf{3 9}$ & $3(6.5)$ & $43(93.5)$ & $46(100)$ \\
\hline $\mathbf{4 0}-\mathbf{5 9}$ & $6(18.8)$ & $26(81.2)$ & $32(100)$ \\
\hline $\mathbf{6 0}-\mathbf{7 9}$ & $12(41.4)$ & $17(58.6)$ & 0.03 \\
\hline$\geq \mathbf{8 0}$ & $1(100)$ & 0 & $1(100)$ \\
\hline Total & $28(21.7)$ & $101(78.3)$ & $129(100)$ \\
\hline
\end{tabular}

${ }^{\mathrm{a}}$ Values are expressed as No (\%).
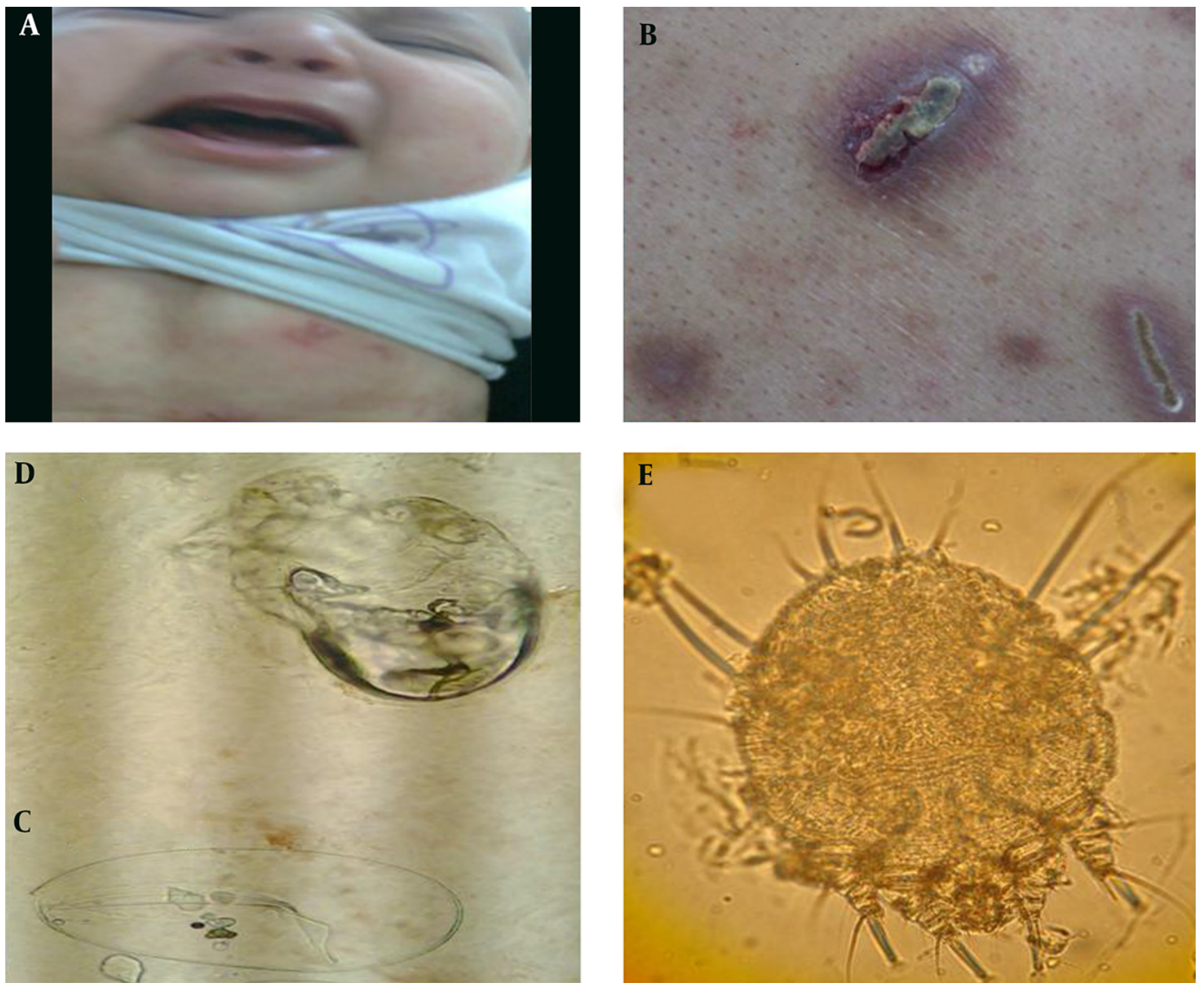

Figure 1. A, Erythematous Papules and Pustules on the Abdomen in a 4 Months Baby; B, Erosive Lesions in a Dialysis Patient; C, D, and E, Microscopic Sections of Skin Scraping with $10 \%$ KOH Showing Eggs, Nymph and Adult S. scabies Mite.

by Poudat and Nasirian [3]. Whereas in Ghezel Hesar prison which is nearby to Tehran was $2.2 \%$ [21]. Scabies infestation in prison is very important, due to the contagious infec- tion. Prisoners, the personnel who worked in the prison and their family could be infested [21]. Leppard et al. reported the highest rate of scabies (95\%) infestation in pris- 
Table 3. Distribution of Clinical Manifestations and Risk Factors Among 28 Positive Cases of S. scabiei Infestations ${ }^{\text {a }}$

\begin{tabular}{lccc}
\hline Symptoms and Signs & Present & Absent & P Value \\
\hline Pruritus & $27(96.4)$ & $1(3.6)$ & 1 \\
Papule & $7(25)$ & $21(75)$ & 0.3 \\
\hline Erosion & $8(28.6)$ & $20(71.4)$ & 0.007 \\
Pustule & $6(21.4)$ & $22(78.6)$ & 0.02 \\
\hline Location & & & \\
$\quad$ Leg & $16(57.1)$ & $12(42.9)$ & 0.9 \\
\hline \multicolumn{1}{c}{ Trunk } & $16(57.1)$ & $12(42.9)$ & 0.53 \\
\multicolumn{1}{c}{ Finger web } & $6(21.4)$ & $22(78.6)$ & 0.11 \\
\hline Number of lesion & & & 0.13 \\
\hline \multicolumn{1}{c}{$7-10$} & $23(82.1)$ & $5(17.9)$ & 0.13 \\
\hline Contact animal & $23(82.1)$ & $5(17.9)$ & \\
\hline
\end{tabular}

${ }^{\mathrm{a}}$ Values are expressed as No (\%).

oners and (26\%) personnel of the prison Tanzania [22]. Documented estimations reveal different rate of infection in other country from $24 \%$ to $40 \%$ in overcrowded populations $[12,23]$. The most crusted forms were diagnosed in children with mentally or physically problems and were HIV positive [24]. The predominant factors for high incidence and prevalence in these countries are unsuitable living conditions, overcrowding and people who have low income and education $[1,18]$. The interfamily transmission was recorded in nineteen (67.8\%) cases that the highest rate of transmission was occurred among sexual partners and the lowest among grandchildren. Sexual relation has an important role in transmission that was similar to other study [15].

In this study the highest incidence of scabies infestation was recorded in spring and winter which was accordance to other study [15]. It's obvious the colder weather in the winter and the early spring is correlated to wear more clothes and have closer contact. Moreover in cooler weather, mites survive longer away from the body and somewhat related to antimicrobial peptides contained in human sweat which are considered as an inhibitor for mite surviving on human body [1]. That is inconsistence with the results of Hussein-Shokouh study [12].

There is a surprising increase in the rate of scabies during 2014, which could be related to more consideration by health system and physicians to prevent and treatment of this infestation.

The results of the current study showed that the highest rate $(41.4 \%)$ scabies infestation belong to the $60-79$ years old and the lowest rate (6.5\%) in 20 - 39 years old (Ta- ble 2), whereas $8.6 \%$ of infected people had less than 7 years old, which was disagreement with other studies $[15,25]$. However, this difference may be due to immunodeficiency disorders in elderly people. The most cases were reported in uneducated people; it could be due to more economic and social problems.

In this study Scabies infestation was more common in rural area (Table 1 ). The reason for the higher rate in this group is the less health attention for preventing infestation.

The most common symptom (96.4\%) was nocturnal pruritus which is in accordance with the study of Akhtar et al. and Leppard et al. [17, 22]. This symptom is due to delayed type-IV hypersensitivity reaction to the mite, its saliva, eggs, or excrements. So that pruritus could be consider as a suspicion of scabies especially when other family members have similar symptoms $[1,26]$.

\subsection{Conclusions}

The results of this study showed that the rate of Sarcoptes infestation in Kashan is high, especially in patients' undergone dialysis. Several factors such as social problems and sexual contact were the most important factors in infestation. So Scabies should be regarded as a major public health problem in Iran and when a case is identified, it should be reported to health care system as soon as possible.

\section{Acknowledgments}

The authors acknowledged wholehearted cooperation of Pro. Hossien Hooshyar and Dr. Mehdi Delavari. This article is based on M.D. thesis of Dr. Elahe Kaveh, Kashan University of Medical Sciences No: P1678.

\section{Footnotes}

Authors' Contribution: The design, samplings and diagnose of Sarcoptes scabie were carried out by Dr. Sima Rasti , Dr. Rezvan Talaee and Dr Mehdi Nazeri. Suspected patients were diagnosed by Dr. Rezvan Talaee. Writing article was carried out by Dr. Sima Rasti and Dr Mehdi Nazeri and Dr. Rezvan Talaee. Data recording was made by Dr. Elahe Kaveh. Statistic analysis was made by Seyed Gholam Abbas Mousavi.

Conflicts of Interest: The authors report no conflicts of interest. 


\section{References}

1. Hengge UR, Currie BJ, Jager G, Lupi O, Schwartz RA. Scabies: a ubiquitous neglected skin disease. Lancet Infect Dis. 2006;6(12):769-79. doi: 10.1016/S1473-3099(06)70654-5. [PubMed: 17123897].

2. Nnoruka EN, Agu CE. Successful treatment of scabies with oral ivermectin in Nigeria. Trop Doct. 2001;31(1):15-8. [PubMed: 11205591].

3. Poudat A, Nasirian H. Prevalence of pediculosis and scabies in the prisoners of Bandar Abbas, Hormozgan province, Iran. PakJ Biol Sci. 2007;10(21):3967-9. [PubMed: 19090266].

4. Alexander JO'D. Arthropods and human skin. Springer Science \& Business Media; 2012.

5. Holness DL, DeKoven JG, Nethercott JR. Scabies in chronic health care institutions. Arch Dermatol. 1992;128(9):1257-60. [PubMed: 1519942].

6. Habif TP, Chapman MS, Campbell Jr JL, Dinulos JGH, Zug KA. Skin disease: diagnosis and treatment. Elsevier Health Sciences; 2011.

7. Burns T, Breathnach S. Rook's Textbook of dermatology Vol 4. London: Blackwell Scientific Publications; 1992.

8. James WD, Elston D, Berger T. Andrew's diseases of the skin: clinical dermatology. Elsevier Health Sciences; 2011.

9. Heukelbach J, Walton SF, Feldmeier H. Ectoparasitic infestations. Curr Infect Dis Rep. 2005;7(5):373-80. [PubMed: 16107235].

10. Badiaga S, Menard A, Tissot Dupont H, Ravaux I, Chouquet D, Graveriau C, et al. Prevalence of skin infections in sheltered homeless. Eur Dermatol. 2005;15(5):382-6. [PubMed:16172049].

11. Tsutsumi M, Nishiura H, Kobayashi T. Dementia-specific risks of scabies: retrospective epidemiologic analysis of an unveiled nosocomial outbreak in Japan from 1989-90. BMC Infect Dis. 2005;5:85. doi 10.1186/1471-2334-5-85. [PubMed: 16225694].

12. Mahtab Noorifard MD, Dabbagh-Moghaddam A. The assessment of epidemiologic aspects of scabies in Iran's Army during 2004 to 2010. Ann Mil Health Sci Res. :163.

13. Pruksachatkunakorn C, Wongthanee A, Kasiwat V. Scabies in Thai orphanages. Pediatr Int. 2003;45(6):724-7. [PubMed:14651549].

14. Gimenez Garcia R, de la Lama Lopez-Areal J, Avellaneda Martinez C. Scabies in the elderly. I Eur Acad Dermatol Venereol. 2004;18(1):105-7. [PubMed: 14678549].
15. Vazirianzadeh B, Dehghani R, Hejazi SH, Jalayer N. Frequency of Sarcoptes scabiei infestation in patients referred to the parasitology laboratory in Isfahan, Iran (1996-2002). Jundishapur J Microbiol. 2009;2(2):65-70.

16. Golchai J, Zargari O, Peinondi Gholipour M, Somesaraee Karbasi M. The prevalence of scabies in the students of primary schools in somea-sara in 2000-2001: An observational cross-sectional study. Iranian J of Dermatol. 2003;25(7):29-32.

17. Akhtar SJ, Maan MA, Iqbal J, Kapadia N. Treatment of scabies simplified.J Pak Assoc Dermatol. 2007;17:240-9.

18. Heukelbach J, de Oliveira FA, Feldmeier H. [Ecoparasitoses and public health in Brazil: challenges for control]. Cad Saude Publica. 2003;19(5):1535-40. [PubMed: 14666235].

19. Jalayer T, Asilian A, Khodaei A. Survey on Sarcoptes scabiei with emphasis on social conditional in Esfahan. 2nd National Congress of Parasitic Diseases.

20. Sharif M, Hezar Jaribi HZ, Haghi F. Prevalence of mange among primary school students in Sari during 1999-2000. J Mazandaran Univ Med Sci. 2003;13:49-53.

21. Rahmati Roodsari M, Malekzad F, Ebrahimzadeh M, Abbasi Alai Ardakani B, Ghoraishian M. Prevalence of scabies and pediculosis in Ghezel Hesar prison, Iran. J Pak Assoc Dermatol. 2006;16:201-4.

22. Leppard B, Naburi AE. The use of ivermectin in controlling an outbreak of scabies in a prison. Br J Dermatol. 2000;143(3):520-3. [PubMed: 10971323].

23. McCarthy JS, Kemp DJ, Walton SF, Currie BJ. Scabies: more than just an irritation. Postgrad Med J. 2004;80(945):382-7. doi: 10.1136/pgmj.2003.014563. [PubMed:15254301].

24. Landwehr D, Keita SM, Ponnighaus JM, Tounkara C. Epidemiologic aspects of scabies in Mali, Malawi, and Cambodia. Int J Dermatol. 1998;37(8):588-90. [PubMed: 9732003].

25. Terry BC, Kanjah F, Sahr F, Kortequee S, Dukulay I, Gbakima AA. Sarcoptes scabiei infestation among children in a displacement camp in Sierra Leone. Public Health. 2001;115(3):208-11. doi: 10.1038/sj/ph/1900748. [PubMed: 11429717].

26. Chosidow O. Scabies and pediculosis. Lancet. 2000;355(9206):819-26. [PubMed: 10711939]. 